\title{
Implementasi Location Based Service Rute Objek Wisata Tegal
}

\author{
Ginanjar Wiro Sasmito ${ }^{1}$, Fuad Hadiansah ${ }^{2}$ \\ ${ }^{1,2}$ Politeknik Harapan Bersama \\ Jln. Mataram No. 09 Tegal \\ ${ }^{1}$ anjar.dosen@ gmail.com, ${ }^{2}$ androidyuzer@gmail.com
}

\begin{abstract}
Abstrak - Tegal merupakan salah satu daerah di Jawa Tengah yang memilik banyak objek wisata yang dikelola oleh pemerintah mapun pihak swasta. Tidak sedikit wisatawan Tegal yang merasa bingung dalam memutuskan untuk mengunjungi tempat wisata yang cocok, ini dikarenakan kurangnya informasi mengenai objek wisata tersebut. Sistem layanan berbasis lokasi atau lebih dikenal dengan Location Based Service (LBS) adalah layanan yang ditawarkan melalui ponsel dengan mempertimbangkan lokasi geografis perangkat tersebut. Karena LBS sangat tergantung pada lokasi pengguna mobile, tujuan utama dari sistem penyedia layanan adalah untuk menentukan di mana pengguna. Sebuah LBS dapat menunjukkan pengguna ke restoran, pom bensin, rumah sakit maupun objek wisata terdekat. Dengan menggunakan LBS maka akan mempermudah wisatawan dalam menentukan tujuan wisata di kota dan kabupaten Tegal berdasarkan lokasi pengguna dengan menggunakan GoogleMaps API V2. Implementasi Location Based Service rute objek wisata Tegal dapat memberikan informasi lokasi objek wisata, titik koordinat dan informasi pendukung mengenai objek wisata yang ada di Tegal.
\end{abstract}

Kata kunci - Tegal, Android, LBS, Maps

\begin{abstract}
Tegal is one of area in Central Java which has many tourism place be managed by Government or private parties. Many tourists from tegal who are confused to decide on appropriate visiting tourist spots, this is due to lack of information about that. Location-based services system or better known as Location Based Service (LBS) is a service offered through mobile phones by considering geographical location of these devices. Because LBS is highly dependent on the location of the mobile user, The main purpose of the service provider system is to determine where the user is located. An LBS can show places such as restaurants, gas stations, hospitals and tourism spots closest to the user. By using LBS then the tourists will be facilitated in determining tourist destinations in the city and district of Tegal based on the user's location using the Google Maps API V2. Implementation of Location Based Service for mapping tourism spot of Tegal can provide information about tourist sites, the coordinates and other supporting information about tourism spot in Tegal.
\end{abstract}

Keywords - Tegal, Android, LBS, Maps

\section{PENDAHULUAN}

Wisata merupakan kebutuhan seseorang untuk menenangkan pikiran dari kepenatan sehari-hari. Berwisata memang merupakan suatu hal yang sangat didambakan, karena dengan berwisata dapat sejenak melupakan keadaan sehari-hari yang monoton. Meskipun kadang membutuhkan dana, namun tidak akan pernah sebanding dengan kepuasan rohani dan jasmani yang didapatkan. Tegal merupakan salah satu daerah yang mempunyai objek wisata yang menarik. Meskipun hanya daerah kecil tidak menutup kemungkinan Tegal dikunjungi oleh wisatawan dari luar Tegal, ini dikarenakan wilayah Tegal yang berupa dataran rendah dan dataran tinggi menjadi keuntungan tersendiri, semua tempat wisata hampir tersebar merata dari ujung utara hingga ujung selatan. Pantai, waduk, perkebunan, bukit hijau, air terjun, sungai, sumber air panas, hutan bisa ditemukan di Tegal [1].
Pesatnya perkembangan dunia pariwisata di daerah Tegal, tidak diiringi dengan perkembangan teknologi yang digunakan. Ditambah lagi dengan kondisi, banyak wisatawan yang tidak mau berwisata karena merasa kurang informasi mengenai objek wisata tersebut. Sehingga hal ini membuat calon wisatawan yang ingin menghabiskan liburannya untuk berwisata kurang pasti dalam memutuskan untuk mengunjungi tempat wisata yang cocok. Untuk itu diperlukan suatu sistem yang dapat memberikan gambaran mengenai tujuan wisata tersebut. Sehingga nantinya dapat membantu dalam menentukan objek wisata yang cocok bagi para wisatawan tersebut. Pemanfaatan teknologi untuk menunjang sektor pariwisata sangat dibutuhkan agar para wisatawan mudah untuk mengakses infomasi tempat wisata.

Pada era komputerisasi saat ini, smartphone adalah barang yang sedang tren. Smartphone merupakan salah satu wujud realisasi ubiquitous computing (ubicomp) dimana teknologi tersebut memungkinkan proses komputasi dapat terintegrasi 
dengan berbagai aktifitas keseharian manusia yang tidak dibatasi oleh satu wilayah tertentu [2]. Diantara banyak smartphone yang beredar sekarang ada beberapa sistem operasi yang mendukung smartphone salah satunya adalah Android. Android merupakan salah satu sistem operasi smartphone yang sedang berkembang saat ini. Android mempunyai banyak keunggulan dibanding sistem operasi lain, antara lain sistem operasi bersifat terbuka dan gratis, oleh karena itu hampir setiap kode program Android diluncurkan berdasarkan lisensi open source Apache yang berarti bahwa semua orang yang ingin menggunakan Android dapat men-download penuh source code-nya. Keuntungan utama dari Android adalah adanya pendekatan aplikasi secara terpadu. Pengembang hanya berkonsentrasi pada aplikasi saja, aplikasi tersebut bisa berjalan pada beberapa perangkat yang berbeda selama masih ditenagai oleh Android (pengembang tidak perlu mempertimbangkan kebutuhan jenis perangkatnya) [3].

Integrasi teknologi mobile GPS dan internet memungkinkan dikembangan aplikasi mobile berbasis lokasi (location based service) yang interaktif. Location based service adalah sistem yang menyebarkan suatu informasi yang dapat diakses menggunakan suatu mobile devices menggunakan internet. Cara mengaksesnya dengan menggunakan GPS yang ada pada mobile device tersebut [4].

Implementasi Location Based Service pada rute objek wisata Tegal sangat dibutuhkan untuk melihat rute objek wisata di Tegal. Implementasi tersebut dinamakan dengan aplikasi Wisata Tegal. Dengan menggunakan aplikasi Wisata Tegal ini diharapkan pengguna bisa terbantu menemukan tempat wisata dan informasi lainnya dari posisi pengguna berada dengan memanfaatkan GPS (Global Positioning System) dan internet.

Location Based Service (LBS) atau layanan berbasis lokasi adalah sebuah layanan informasi yang dapat diakses dengan perangkat bergerak melalui jaringan dan mampu menampilkan posisi secara geografis keberadaan perangkat bergerak tersebut. Location Based Service dapat berfungsi sebagai layanan untuk mengidentifikasi lokasi dari seseorang atau suatu objek tertentu, seperti menemukan lokasi SPBU terdekat atau lokasi lainnya [5].

Location Based Service (LBS) atau layanan berbasis lokasi ini diterapkan dalam sebuah platform android. Android adalah sistem operasi bergerak (mobile operating system) yang mengadopsi sistem operasi Linux, namun telah dimodifikasi” [6].

Android sering disebut sebagai generasi baru platform mobile, platform yang memberikan pengembang untuk melakukan pengembangan sesuai yang diharapkannya. Sistem operasi yang mendasari Android dilisensikan di bawah GNU, General Public Lisensi Versi 2 (GPLv2), yang sering dikenal dengan istilah "copyleft" lisensi dimana setiap perbaikan pihak ketiga harus terus jatuh di bawah terms. Android didistribusikan dibawah Lisensi Apache Software (ASL/Apache2), yang memungkinkan untuk distribusi kedua dan seterusnya. Hal yang menarik, Android tidak hanya ditujukan untuk ponsel, tetapi juga perangkat elektronik bergerak lainnya [7].

Lapisan aplikasi Android sangat berbeda dibandingkan dengan sistem operasi lainnya. Pada Android semua aplikasi, baik aplikasi inti (native) maupun aplikasi pihak ketiga berjalan diatas lapisan aplikasi dengan menggunakan pustaka API (Application Programming Interface) yang sama [8].

Libraries pada android adalah layer dimana fiturfitur Android berada, biasanya para pembuat aplikasi mengakses libraries untuk menjalankan aplikasinya. Berjalan diatas kernel, layer ini meliputi berbagai library $\mathrm{C} / \mathrm{C}++$ inti seperti Libc dan SSI, serta.

1. Libraries media untuk pemutaran media audio dan video.

2. Libraries untuk manajemen tampilan.

3. Libraries Graphics mencakup SGL dan Open $G L$ untuk grafis $2 D$ dan $3 D$.

4. Libraries SQLite untuk dukungan database.

5. Libraries SSL dan WebKit terintegrasi dengan web browser dan security.

6. Libraries LiveWebcore mencakup modern web browser dengan engine embeded web view.

7. Libraries 3D yang mencakup implementasi OpenGL ES 1.0 API's.

Pustaka-pustaka tersebut bukanlah aplikasi yang berjalan sendiri, namun hanya dapat digunakan oleh program yang berada di level atasnya. Sejak versi Android 1.5, pengembang dapat membuat dan menggunakan pustaka sendiri menggunakan Native Development Toolkit (NDK) [9].

\section{METODOLOGI PENELITIAN}

Metode penelitian sangat dibutuhkan berkaitan dengan kegiatan penelitian, dimana memuat beberapa hal yaitu bahan penelitian, alat penelitian dan prosedur penelitian.

\section{A. Bahan Penelitian}

Bahan-bahan yang digunakan untuk penelitian ini adalah berupa data-data seperti.

1. Data letak objek wisata di kota dan kabupaten Tegal.

2. Data keterangan objek wisata di kota dan kabupaten Tegal.

3. Data titik koordinat posisi objek wisata di kota dan kabupaten Tegal.

\section{B. Alat Penelitian}

Alat penelitian yang digunakan untuk mendukung kegiatan penelitian ini adalah sebagai berikut. 
1. Perangkat Keras (Hardware)

a. Notebook dengan spesifikasi :

$>$ Intel Pentium (R) Dual-Core CPU T4500@2.30 Ghz 2.30 Ghz

$>$ RAM : $3 \mathrm{~Gb}$

$>$ HDD : $250 \mathrm{~Gb}$

b. Smartphone Android dengan spesifikasi :

$>$ Mediatek MT6572 1.30 Ghz

$>$ RAM : $512 \mathrm{Mb}$

$>$ Android Jellybean 4.2.2

2. Perangkat Lunak (Software)

a. Sistem Operasi Windows 7

b. Java Development Kit (JDK) $7 u 25$

c. IDE Eclipse Kepler (4.3.2)

d. Android Developer Tools 22.3.0 (ADT) Plugins

e. Android Software Development Kit 19.0.1 (SDK)

f. Hypertext Preprosesor (PHP)

\section{Prosedur Penelitian}

Selama ini tidak sedikit wisatawan Tegal merasa kebingungan dalam memutuskan untuk mengunjungi tempat wisata yang cocok dikarenakan kurangnya informasi mengenai objek wisata tersebut.

Berdasarakan identifikasi masalah, maka dibutuhkan suatu solusi terhadap masalah tersebut yaitu dengan memberikan gambaran dan informasi mengenai tujuan wisata tersebut. Untuk menghasilkan solusi permasalahan tersebut maka dibutuhkan beberapa tahapan, diantaranya adalah pengumpulan data. Metode yang digunakan dalam pengumpulan data adalah sebagai berikut.

1. Metode Wawancara

Dalam metode ini dilakukan wawancara dengan bertanya langsung kepada narasumber yang dianggap dapat memberikan informasi secara akurat. Kepala Dinas Pemuda Olahraga Kebudayaan dan Pariwisata Kota Tegal serta Kepala Dinas Pariwisata dan Kebudayaan Kabupaten Tegal adalah orang yang tepat untuk dijadikan narasumber karena mengetahui seluruh data tentang objek wisata di Tegal.

2. Metode Studi Pustaka/Studi Literatur Dalam metode ini, pengumpulan data dilakukan dengan cara mempelajari data objek wisata, tempat objek wisata sekaligus titik koordinat posisi tempat wisata di kota dan kabupaten Tegal. Dan juga mempelajari dari sumber data lain seperti buku-buku referensi, jurnal, website atau penelitian sebelumnya yang berkaitan dengan objek wisata.

Analisa data dalam penelitian ini dilakukan dengan mengumpulkan informasi melalu wawancara maupun studi pustaka, kemudian melakukan reduksi yaitu langkah untuk memilih informasi mana yang sesuai (valid) dan tidak sesuai dengan masalah penelitian yang dilakukan.

\section{ANALISA DAN PERANCANGAN}

\section{A. Analisa Permasalahan}

Implementasi Location Based Service rute objek wisata Tegal dibuat dengan tujuan untuk membantu pengguna menemukan tempat wisata dan informasi lainnya di kota dan kabupaten Tegal. Implementasi tersebut bisa dikatakan sebagai aplikasi Wisata Tegal. Aplikasi ini dibuat berbasis Android karena Android berbasis open source (terbuka) dan freeware (gratis). Dengan memanfaatkan GPS (Global Positioning System) dan internet aplikasi Wisata Tegal akan menampilkan posisi pengguna menggunakan GoogleMaps API V2 dan menyajikan beberapa informasi tentang objek wisata di kota dan kabupaten Tegal.

Dengan adanya aplikasi Wisata Tegal maka pencarian informasi mengenai objek wisata yang ada di kota dan kabupaten Tegal akan lebih mudah, cepat dan akurat. Dalam perancangan sistem yang akan dihasilkan, aplikasi harus mudah digunakan oleh pengguna (user friendly) agar informasi mudah dimengerti dan dipahami oleh pengguna secara maksimal.

\section{B. Perancangan Sistem}

Adapun perancangan sistem dalam pembuatan implementasi Location Based Service rute objek wisata Tegal menggunakan usecase. Usecase merupakan diagram yang menunjukkan hubungan antara aktor dan permasalahan yang ada. [10] Use case digunakan untuk analisis dan desain sistem, Usecase dapat menggambarkan interaksi antara pengguna sistem dengan sistem itu sendiri, dengan memberikan narasi terhadap sistem yang digunakan [11]. Rancangan sistem tersebut ditunjukkan pada Gambar 1 sampai Gambar 4.

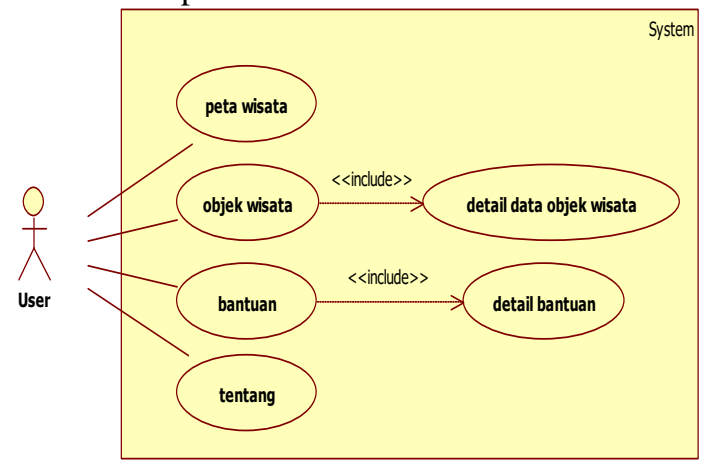

Gambar 1. Rancangan Use Case Diagram 


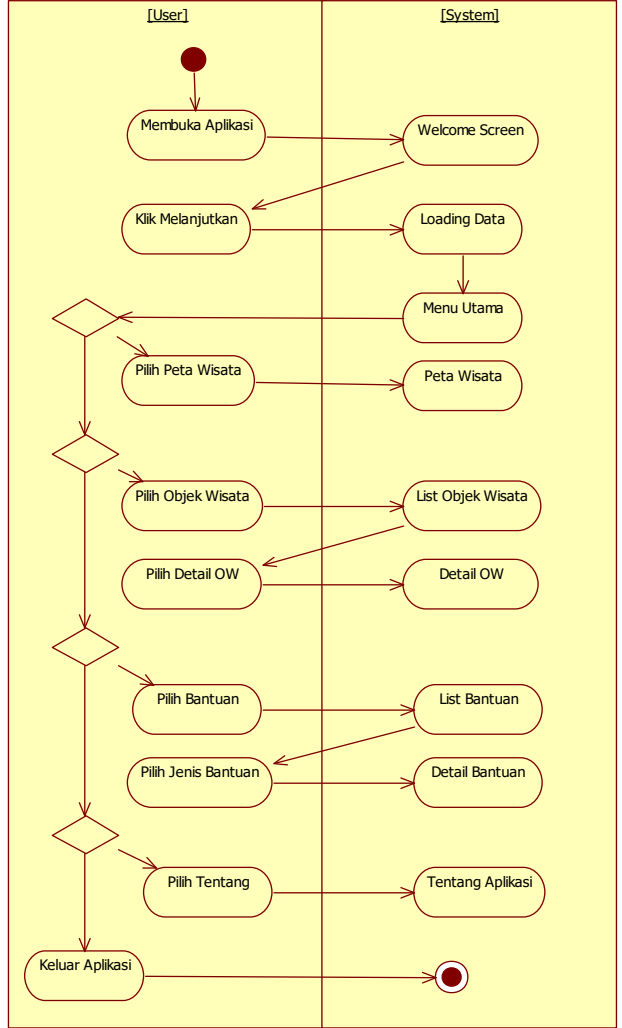

Gambar 2. Rancangan Activity Diagram

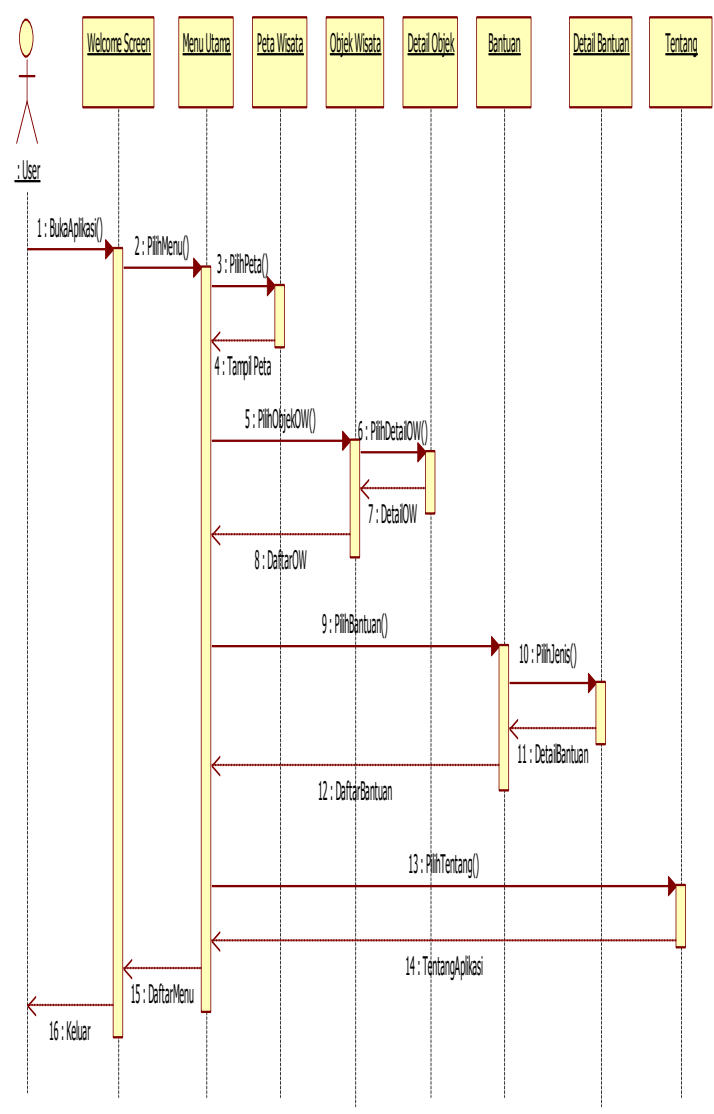

Gambar 3. Rancangan Squence Diagram

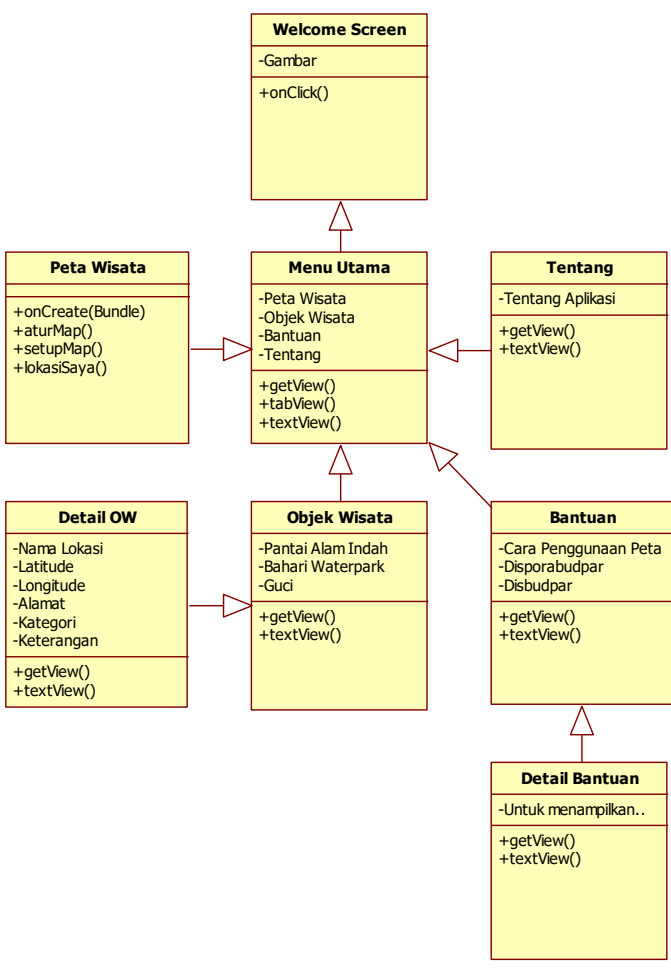

Gambar 4. Rancangan Class Diagram

\section{HASIL DAN IMPLEMENTASI}

A. Implementasi Tampilan Pengguna

1. Welcome Screen

Welcome Screen merupakan tampilan pertama setelah program dijalankan sebelum masuk ke tab menu utama.

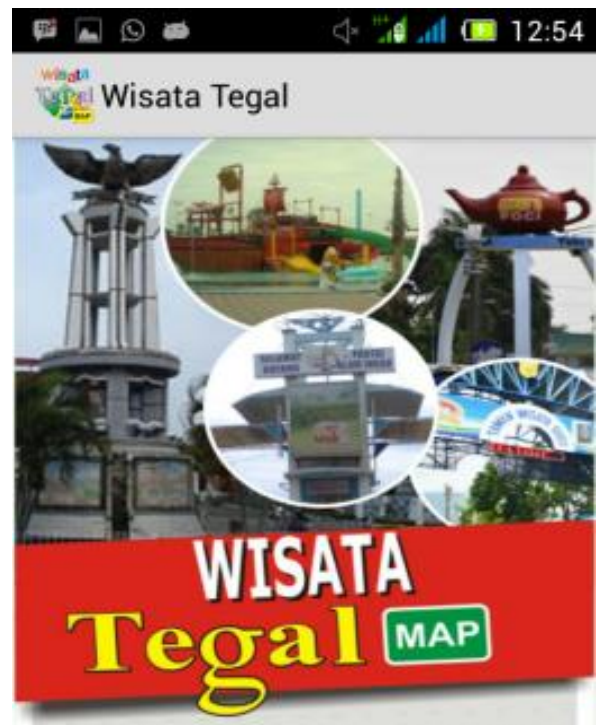

Pastikan internet dan GPS aktif, Sentuh untuk melanjutkan

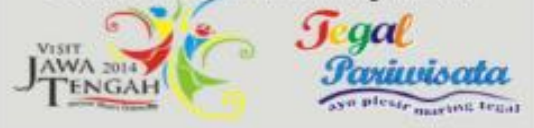

Gambar 5. Tampilan Welcome Screen 
2. Tampilan Peta Wisata

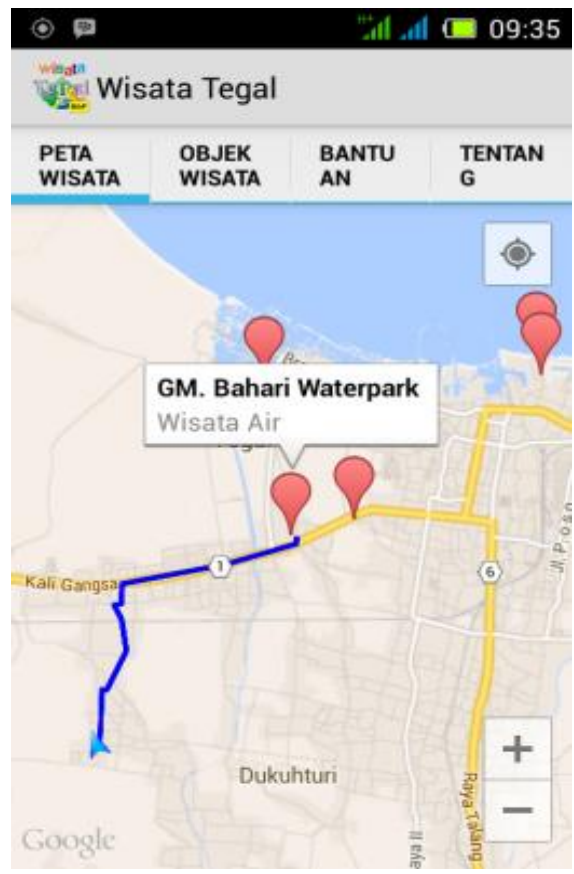

Gambar 6. Tampilan Rute Peta Wisata

3. Tampilan Objek Wisata

\begin{tabular}{|c|c|c|c|}
\hline \multicolumn{4}{|c|}{ 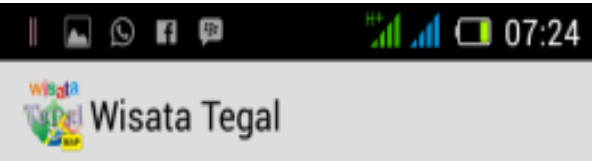 } \\
\hline $\begin{array}{l}\text { PETA } \\
\text { WISATA }\end{array}$ & $\begin{array}{l}\text { OBJEK } \\
\text { WISATA }\end{array}$ & $\begin{array}{l}\text { BANTU } \\
\text { AN }\end{array}$ & $\begin{array}{l}\text { TENTAN } \\
G\end{array}$ \\
\hline \multicolumn{4}{|c|}{$\begin{array}{r}\text { Pantai Alam Indah (PAI) } \\
\text { Wisata Alam }\end{array}$} \\
\hline \multicolumn{4}{|c|}{ Monumen Bahari } \\
\hline \multicolumn{4}{|c|}{ Pantai Muarareja } \\
\hline \multicolumn{4}{|c|}{$\begin{array}{r}\text { GM. Bahari Waterpark } \\
\text { Wisata Air }\end{array}$} \\
\hline \multicolumn{4}{|c|}{ Rita Park } \\
\hline \multicolumn{4}{|c|}{ Purwahamba Indah } \\
\hline
\end{tabular}

Gambar 7. Tampilan Objek Wisata
4. Tampilan Detail Objek Wisata

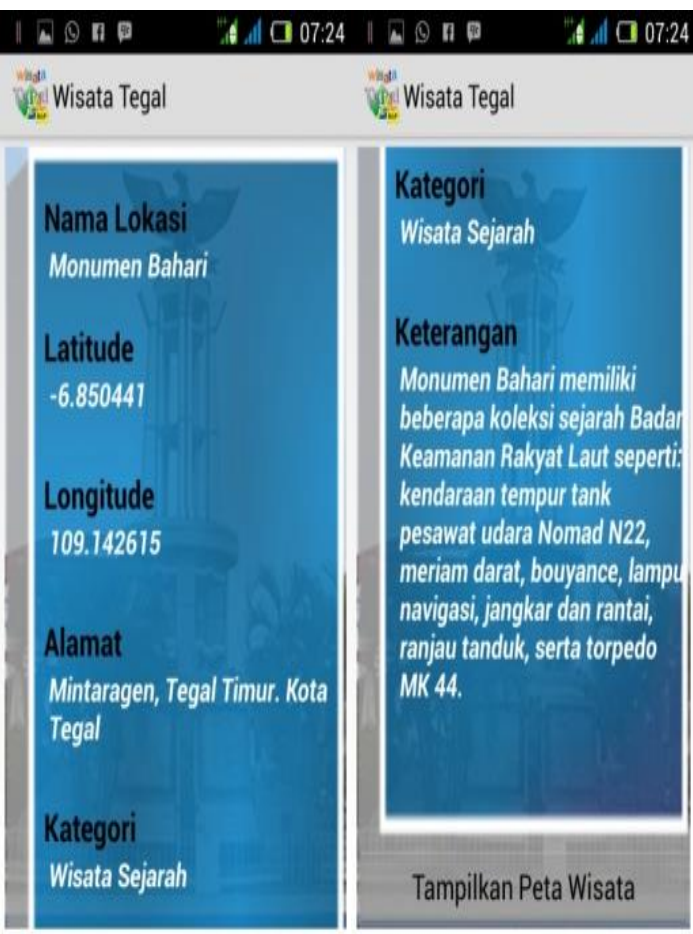

Gambar 8. Tampilan Detail Objek Wisata

5. Tampilan Bantuan

\begin{tabular}{|c|c|}
\hline$F \theta$ & 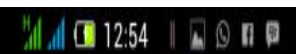 \\
\hline
\end{tabular}

Wist Wisata Tegal
$\begin{array}{llll}\text { PETA OBJEK } & \text { BANTU } & \text { TENTAN } \\ \text { WISATA } & \text { WISATA } & \text { AN } & 6\end{array}$

Wistata Tegal

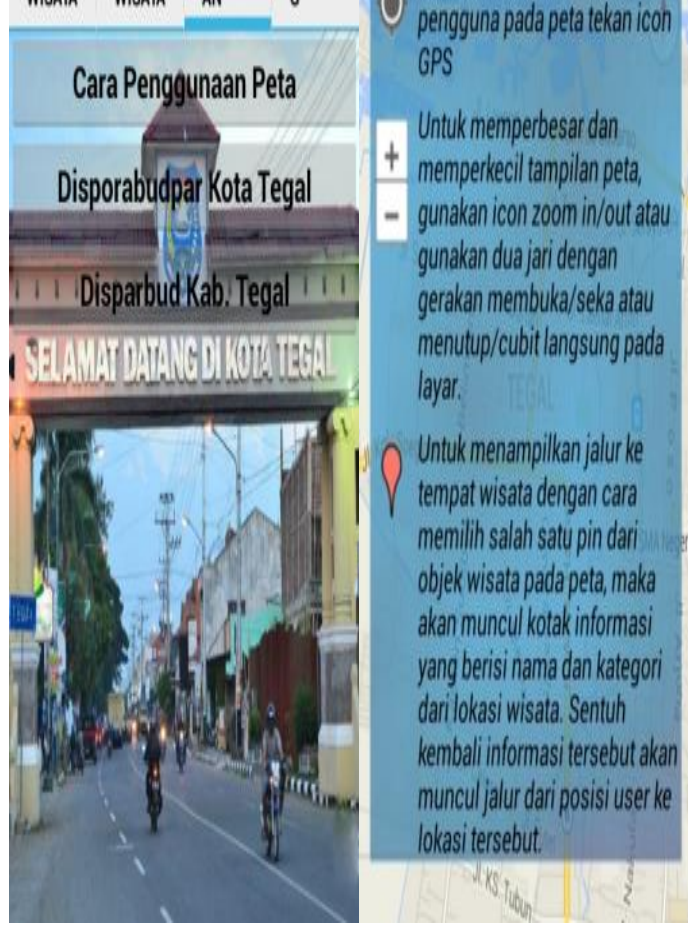

Gambar 9. Tampilan Bantuan 
6. Tampilan Tentang

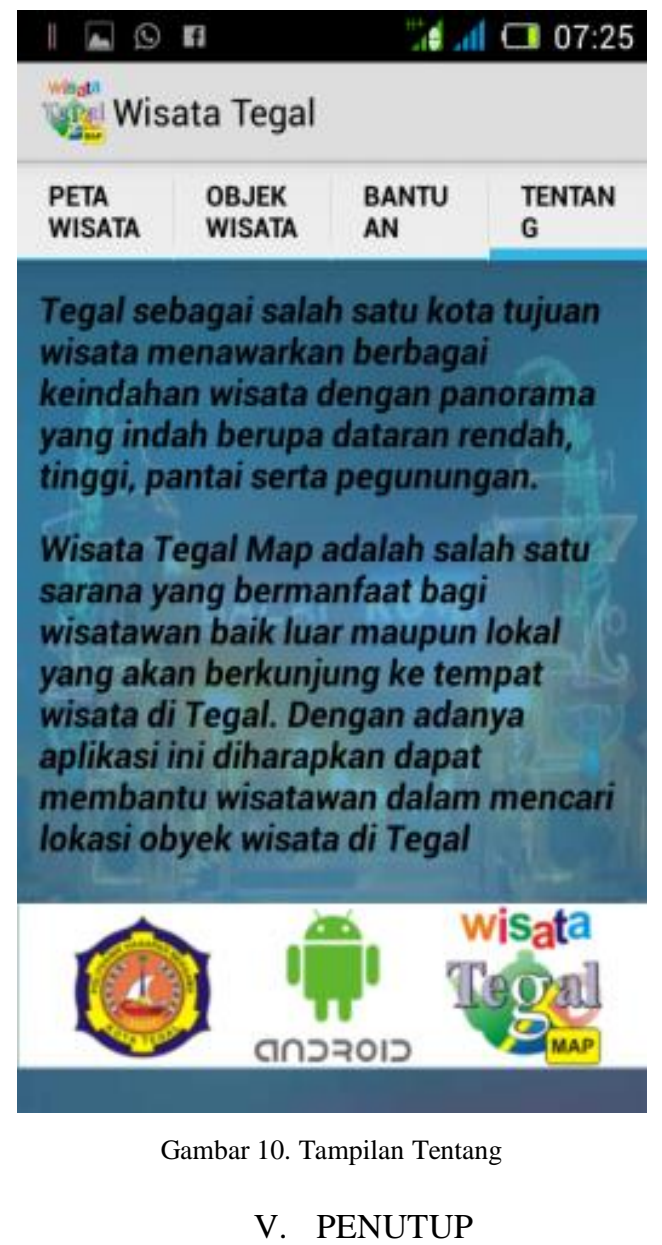

A. Kesimpulan

1. Hasil implementasi Location Based Service rute objek wisata Tegal adalah berupa sebuah aplikasi Wisata Tegal berbasis android.

2. Aplikasi Wisata Tegal dapat menyimpan cache peta pada perangkat, sehingga pengguna dapat melihat letak objek wisata pada perangkat meski dalam keadaan tidak terkoneksi internet. Namun demikian, untuk pencarian rute masih tetap memerlukan koneksi internet.

3. Dengan adanya aplikasi Wisata Tegal, masyarakat menjadi lebih mudah dalam mencari rute dan informasi objek wisata di kota dan kabupaten Tegal.

B. Saran

1. Hasil implementasi Location Based Service rute objek wisata Tegal dioptimalkan agar dapat bersifat multiplatform

2. Sosialisasi tentang aplikasi Tegal Wisata perlu di rencanakan dengan baik, sehingga masyarakat umum dengan mudah mengenal aplikasi ini.

\section{DAFTAR PUSTAKA}

[1] Tegal Wisata. 2015. [online] Tersedia : http://wisatategal.com/ [15 Oktober 2015]

[2] Istiyanto, Jazi Eko. 2013. Pemrograman Smartphone menggunakan SDK Android dan Hacking Android. Yogyakarta. Graha Ilmu

[3] Safaat, Nazruddin. 2012. Pemograman Aplikasi Mobile Smartphone dan Tablet PC Berbasis Android. Bandung : Informatika

[4] Yuliana.2013. Location Based Service. [Online] Tersedia http://yuliana.lecturer.pens.ac.id/Android/Materi/Goo gle\%20Map/LBS\%202013.pdf [15 Oktober 2015]

[5] Widyatama. 2015. [online] Tersedia : http://repository.widyatama.ac.id/xmlui/bitstream/han dle/123456789/3520/Bab\%202.pdf?sequence $=7 \quad[15$ Oktober 2015]

[6] Suprianto, Dodit dan Agustina, Rini. 2012. Pemrograman Aplikasi Android. Malang : Mediakom

[7] Kadir, Abdul. 2013. Pemrograman Aplikasi Android. Yogyakarta. Andi.

[8] Developer Android. 2014. ADT Plugin. [Online ]. Tersedia :

http://developer.android.com/tools/sdk/eclipseadt.html. [4 Mei 2014]

[9] Haryanto, Agus. 2014. Belajar Android Menampilkan Map dengan Android GoogleMaps API V2. [Online]. Tersedia : http://agusharyanto.net/wordpress/?p=893. [4 Mei 2014]

[10] Ambler, Scott. W. 2005. The Elements of UML 2.0 Style. Cambridge University Press.

[11] Fowler, Martin. 2004. UML Distilled (Third Edition). Addison-Wesley 